\title{
Zootekni/Animal Science
}

Araştırma Makalesi / Research Article

Geliş tarihi / Received: 24-11-2020

Kabul tarihi / Accepted: 26-12-2020

Atıf İçin: Ayaşan T, Sucu E, Ülger İ, İnci H, Hızlı H, İnan S, 2021. İn Vitro Gaz Üretim Tekniği Kullanılarak Yer bademi (Cyperus esculentus) Çeşitlerinin Besin Değerinin Saptanması. Iğdır Üniversitesi Fen Bilimleri Enstitüsü Dergisi, 11(2): 1653-1663.

To Cite: Ayaşan T, Sucu E, Ülger İ, İnci H, Hızlı H, İnan S, 2021. Determination of Nutritional Values of Different Tiger nut (Cyperus esculentes) Types by Using In Vitro Gas Production Technique. Journal of the Institute of Science and Technology, 11(2): 1653-1663.

Ín Vitro Gaz Üretim Tekniği Kullanılarak Yer bademi (Cyperus esculentus) Çeşitlerinin Besin Değerinin Saptanması

\author{
Tugay AYAŞAN ${ }^{*}$, Ekin SUCU², İsmail ÜLGER ${ }^{3}$, Hakan İNCİ ${ }^{4}$, Hatice HIZLI ${ }^{5}$, Sevda İNAN ${ }^{6}$
}

ÖZET: Bu çalışmada, farklı yer bademi çeşitlerinin (Sarı şeker, İntrodüksiyon 1, Bal yumru) besin madde değerlerinin ve koçlarda sindirilebilirliklerinin belirlenmesi amaçlanmıştır. Farklı yer bademi çeşitlerinin ortalama gaz üretimi, 96 saatlik inkübasyondan sonra in vitro gaz üretim kinetiği ve in vitro inkübasyon süreleri belirlenmiştir. Yetiştirilen farklı yer bademi çeşitlerinin in vitro gaz üretim tekniği kullanılarak a, b, c, a + b'nin pearson korelasyon katsayıları ve pearson korelasyon katsayıları bulunmuştur. Çalışmada farklı yer bademi çeşitlerinin değişik zamanlardaki ortalama gaz üretimleri sadece 3. saatte önemli bulunmuş; 96 saatlik inkübasyondan sonraki in vitro gaz üretim kinetikleri, çeşitler arasında farklılık yaratmamış; in vitro inkübasyon zamanları ile pearson korelasyon katsayıları arasındaki ilişki önemli tespit edilmiştir. Yer bademi çeşitlerinin ortalama ham proteini (HP) \%4.39; kuru maddesi (KM) \%94.08; ham yağı (HY) \%24.85; ham külü (HK) \%2.53; asit deterjanda çözünmeyen lif (ADF) \%15.04, nötr deterjanda çözünmeyen lif (NDF) \%24.03; lif olmayan karbonhidrat (LOK) \%44.20 olarak bulunmuştur. Yer bademi çeşitlerinin ortalama toplam sindirilebilir besin maddesi \%72.78; metabolik enerjisi 2.63 Mcal/kg KM, sindirilebilir enerjisi 3.21 Mcal/kg KM ve de net enerji laktasyon değeri $1.66 \mathrm{Mcal} / \mathrm{kg} \mathrm{KM}$ olarak tespit edilmiştir.

Anahtar Kelimeler: Besin madde, çeşit, in vitro gaz üretimi, koç, sindirilebilirlik, yer bademi

\section{Determination of Nutritional Values of Different Tiger nut (Cyperus esculentus) Types by Using In Vitro Gas Production Technique}

\begin{abstract}
In this study, it was aimed to determine the nutritive values and digestibility (in ram) of different tiger nut varieties (Sarı şeker, İntrodüksiyon 1, Bal yumru). The average gas production at different times of tiger nut varieties, the in vitro gas production kinetics after 96 hours of incubation and the in vitro incubation times were determined. Pearson correlation coefficients and pearson correlation coefficients of $\mathrm{a}, \mathrm{b}, \mathrm{c}, \mathrm{a}+\mathrm{b}$ of different tiger nut varieties by using in vitro gas production technique were found. The tiger nut varieties used in the study are Sarı şeker, İntrodüksiyon 1 and Bal yumru. In the study, average gas production of tiger nut varieties at different times was found important only at $3^{\text {rd }}$ hour; in vitro gas production kinetics after 96 hours of incubation did not differ between cultivars; the relationship between in vitro incubation times and pearson correlation coefficients was determined significantly. The average crude protein, dry matter, ether extract, crude ash, neutral detergent fiber (NDF), acid detergent fiber (ADF) and non-fiber carbohydrates (NFC) of the tiger nut varieties were found $4.39 ; 94.08 ; 24.85 ; 2.53 ; 24.03 ; 15.04 ; 44.20 \%$. In this study, average total digestibility nutrients, digestible energy, metabolizable energy and net energy lactation of tiger nut varieties were found as $72.78 \%, 3.21 \mathrm{Mcal} / \mathrm{kg} \mathrm{DM}, 2.63 \mathrm{Mcal} / \mathrm{kg} \mathrm{DM}$ and $1.66 \mathrm{Mcal} / \mathrm{kg} \mathrm{DM}$.
\end{abstract}

Keywords: Nutrient composition, variety, in vitro gas production, ram, digestibility, tiger nut

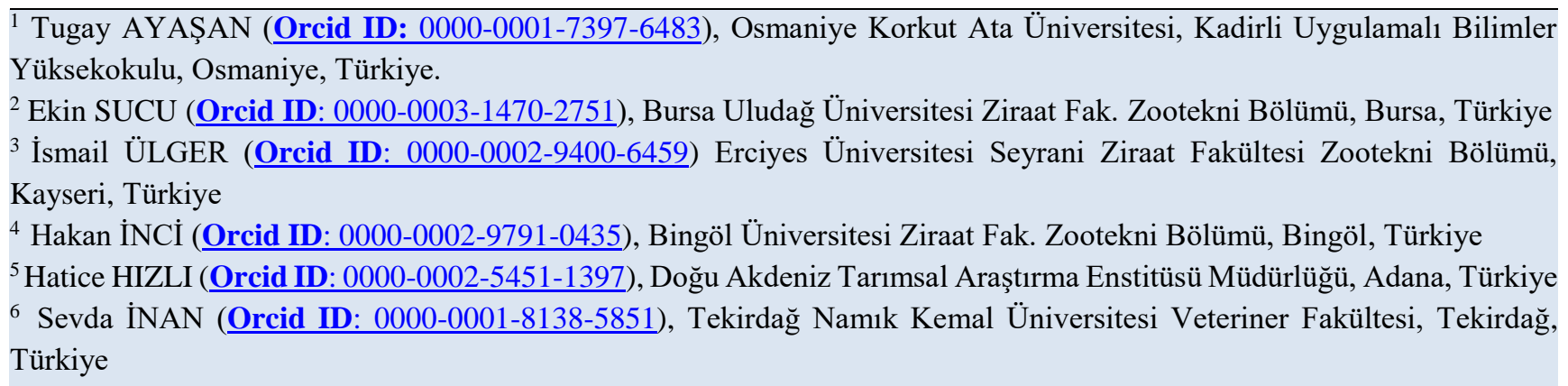

*Sorumlu Yazar/Corresponding Author: Tugay AYAŞAN, e-mail: tayasan@gmail.com 


\section{GíRiș}

Yer bademi (Cyperus esculentus L.,) tropikal ve 1lıman bölgelerde yetişen ve aynı zamanda doğada da bulunan bir bitki olup; çufa, habbülleziz, sarı topalak gibi isimlerle de ifade edilmektedir (Sidohounde ve ark., 2014; Bilgili ve ark., 2018; Anonim, 2019a; Anonim, 2019b; Y1lmaz, 2019). Yer bademinin toprak altı yumrusuna çufa ismi verilmektedir. Yer bademinin tüketilme şekilleri taze olarak, suda islatılarak, kavurma ya da kurutma şeklindedir.

Ülkemizde Adana'da Doğu Akdeniz Tarımsal Araştırma Enstitüsü’nde çok az miktarda ekimi yapılan yer bademinin, İspanya'da yumruları insan gıdası olarak tüketilirken; ilaç, parfümeri sektöründe, balık yemi, hindi ve piliç yemi yapımında kullanıldığına dair bilgiler de bulunmaktadır (Nazlıcan, 2007).

Emurotu (2017), yer bademindeki KM içeriğinin çeşitlere göre farklılık arz ettiğini, sarı yer bademinde \%88 olan KM içeriğinin, kahverengi çeşitte \%89.98 olduğunu ifade ederken; İnce ve ark., (2017), yer bademinin besin madde kompozisyonu ile ilgili çalışmaların bulunduğunu, fakat fiziksel özellikleri hakkında yapılan çalışmaların az olduğunu bildirmiştir. Bu konuda yapılan bir başka çalışmada farklı işleme yöntemlerinin yer bademinin besin madde içeriği üzerine etkisi araştırılmıştır (Aduwamai ve ark., 2018). Araştırıcılar işlem görmemiş yer bademi ile ıslatılmış yer bademinin benzer şekilde KM (\%90.63), HP (\%17.33) ve HY içerdiğini (\%10.17); buna karşılık kül içeriğinin işlem görmemiş yer bademinde daha fazla olduğu (\%7.17'ye \%7.12); karbonhidrat içeriğinin ise 1slatılmış yer bademinde daha fazla bulunduğu tespit edilmiştir. Kurutulmuş yer bademinde KM \%93.67; HP \%13.73, yağ \%8.00, kül \%5.47 olarak bulunmuştur. Madaki ve ark., (2018), işlem görmüş ve görmemiş yer bademini karş1laştırdıkları çalışmalarında, \%7.24-8.39 HP, \%25.53-28.61 HY, \%22.34-24.94 HS ve \%90.33-92.14 KM tespit edildiğini, işlem görmemiş yer bademinin daha fazla HP, HY, HS içerdiğini bildirmiştir. Suleiman ve ark., (2018)'da, yer bademinin yapısında \%42.4 nem, \%17.82 karbonhidrat, \%13.1 HS, \%17 HY, \%8.51 HP olduğunu ifade etmiştir.

Yemlerde besinsel özellikler bakımından farklılıkların belirlenmesinde, yemlerin kimyasal kompozisyonu, metabolik enerji ve sindirilebilir besin maddelerinin belirlenmesi büyük önem taşımaktadır (Ülger ve Kaplan, 2016; Ayaşan ve ark., 2018). Yemlerin enerji ve sindirilebilir besin maddelerinin belirlenmesinde genellikle in vivo yöntemler kullanılmasına rağmen bu yöntemlerin zaman alıcı ve pahalı olmasından dolayı son zamanlarda in vitro gaz üretim tekniği ve kimyasal kompozisyonu ile yemlerin potansiyel besleme değerleri ortaya konulmaya çalışılmaktadır (Kamalak ve ark., 2011; Kara, 2020).

Son yıllarda bir çok araştırmacı alternatif yem kaynakları hakkında araştırmalar yapmaktadır (Kaya ve ark., 2016; Turan ve Soycan Önenç, 2018; He ve ark., 2019; Eseceli ve ark., 2020; Gutierrez ve Boyd, 2020; Ortiz ve Roa Vega, 2020; Türel ve Buğdayc1, 2020; Ülger ve ark., 2020a; Ülger ve ark., 2020b).

Ayaşan ve ark. (2020), yer bademinin enerjice yoğun bir yem olduğunu, bununla birlikte, rasyonda yüksek seviyede bulunan yağlarının rumendeki mikroplar için toksik olabileceğini ve lif sindirilebilirliğini etkileyebileceğini ifade ederken; yer bademi ile beslenen geviş getiren hayvanlar için rasyonların formüle edilmesinde yer bademinin yağ içeriğinin dikkate alınması gerektiğini bildirmişlerdir.

Yapılan literatür çalışmalarında yer bademine ait in vitro sindirilebilirlik çalışmalarının çok az olduğu görülmüştür. Bu nedenle, yapılan bu çalışma ile 3 farklı yer bademi çeşidinin besin değerinin in vitro gaz üretim tekniği ile saptanması amaçlanmıştır.

\section{MATERYAL VE METOT}

\section{Hayvan ve Yem Materyali}

Bu çalışmada Adana Doğu Akdeniz Tarımsal Araştırma Enstitüsü Doğankent lokasyonunda yetiştirilen yer bademi çeşitleri kullanılmıştır. Araştırma enstitüsü, 36 49'00" Kuzey (K) enlemi ve 35 16'00" Doğu (D) boylamı koordinatlarında yer almaktadır. Yer bademinin ekimi Nisan 2018'de 
yapılmış olup; yetiştirme süresi 5-6 ay sürmüştür. Tüm örnekleri temsil edecek şekilde yer bademinden her bir çeşit bazında 3 tekerrür alınarak analizler için hazırlanmıştır.

Çalışmada, çeşitli yer bademlerinin in vitro gaz üretim tekniği ile besin madde içeriklerini belirlemek amacıyla yaklaşık 70 kg canlı ağırlığa sahip iki baş Kıvırcık ırkı koç kullanılmıştır.

Bursa Uludağ Üniversitesi Ziraat Fakültesi Tarımsal Uygulama ve Araştırma Merkezi’nde barındırılan deneme hayvanları araştırmaya başlamadan bir hafta önce seçilmiş olup; hayvanlar bundan sonra işletmede hazırlanmış olan kırık buğday, ayçiçeği tohumu küspesi ile vitamin-mineral karması ve mermer tozundan oluşan yoğun yem karmasıyla birlikte, mısır silajıyla beslenmişlerdir. Her bir hayvanın tüketeceği günlük yem miktarı iki eşit parçaya ayrılarak, sabah ve akşam olmak üzere iki ögünde verilmiştir. Hayvanlar bireysel olarak barındırılmış ve önlerinde sürekli temiz içme suyu bulundurulmuştur. Hayvanlara yapısında $\% 18$ ham protein ve $2750 \mathrm{kcal} / \mathrm{kg}$ metabolik enerji içeren yem verilmiştir. Rumen sıvısı, özafagustan rumene indirilen yumuşak bir hortum ve pompa yardımıyla vakum yaptırılarak alınmıştır. Daha sonra rumen sıvısı bir termos içerisinde (39 ${ }^{\circ} \mathrm{C}^{\prime}$ ye ayarlı) laboratuvara getirilip, sıcaklığını kaybetmeden 2 kat tülbent bezinden süzülmüştür.

\section{Yem Analizleri}

Araştırmada yem analizleri Erciyes Üniversitesi Seyrani Ziraat Fakültesi Zootekni Bölümü yem laboratuvarında yapılmıştır. Söz konusu kuru yem örnekleri $1 \mathrm{~mm}$ elek çapına sahip değirmende öğütülmüş; KM içeriği için öğütülmüş örnekler 24 saat süreyle $70{ }^{\circ} \mathrm{C}$ sicaklıktaki etüvde bekletilerek, etüvden sonraki örnek ağırlığı ile ilk ağırlık arasındaki fark bulunup, yüzde olarak hesaplanması ile analiz sonucu tespit edilmiştir. Ham kül içeriği için örnekler $550^{\circ} \mathrm{C}$ 'de 4 saat kül firınında yakılmıştır. Ham protein içeriği hesaplanırken; Kjeldahl metodundan yararlanılırken (AOAC, 1990); HY analizi AOAC (1990) tarafindan bildirilen yönteme göre SER148 Soxhlet (Velp Scientifica, Milano, İtalya) cihazı ile yapılmıştır. Nötr deterjanda çözünmeyen lif (NDF), asit deterjan solüsyonunda çözünmeyen lif (ADF) ve asitte çözünmeyen lignin (ADL) içerikleri Van Soest ve ark. (1991) tarafindan bildirilen yönteme göre ANKOM 200 fiber analizör (ANKOM Teknoloji, NY, ABD) ile saptanmıştır. Hemiselüloz (HES) değerlerinin hesaplanmasında bir eşitlikten (\%Hemiselüloz=\%NDF-\%ADF) yararlanılmıştır (Van Soest ve Wine, 1967). Lifsiz karbonhidrat (LOK) içeriği ise bir başka eşitlik ile hesaplanmıştır (Weiss ve ark. 1992). Toplam sindirilebilir besin maddesi (TSBM), SE, ME ve NEL değerleri aşağıda gösterilen eşitlikler ile hesaplanmıştır (MAFF, 1984):

$\operatorname{TSBM}(\%)=27.66 \times \mathrm{ME}(\mathrm{Mcal} / \mathrm{kg} \mathrm{KM})$

$\mathrm{SE}(\mathrm{Mcal} / \mathrm{kg} \mathrm{KM})=0.04409 \times \mathrm{TSBM}(\%)$

$\mathrm{ME}(\mathrm{Mcal} / \mathrm{kg} \mathrm{KM})=[3227-\{35.85 \times \mathrm{ADF}(\%)+33.46 \times \mathrm{HP}(\%)-35.85 \times \mathrm{HK}(\%)\} / 1000]$

$\mathrm{NEL}(\mathrm{Mcal} / \mathrm{kg} \mathrm{KM})=\{0.0245 \times \operatorname{TSBM}(\%)\}-0.12$

(TSBM: toplam sindirilebilir besin maddesi, ME: metabolize olabilir enerji, SE: sindirilebilir enerji, KM: kuru madde, ADF: asit deterjan çözeltisinde çözünmeyen lif, HP: ham protein, HK: ham kül, NEL: net enerji laktasyon)

\section{In vitro Gaz Üretim Tekniği}

Yer bademlerinin, in vitro koşullarda gaz üretim parametreleri Menke ve Steingass (1988) tarafından tanımlanan “Gaz Üretim Tekniği” kullanılarak Bursa Uludağ Üniversitesi Ziraat Fakültesi Zootekni Bölümü laboratuvarında belirlenmiştir. Yöntemde yemlerin gaz üretimini saptayabilmek için $100 \mathrm{~mL}$ hacimli özel cam şırıngalar (Model Fortuna, Häberle Labortechnik, Lonsee-Ettlenschie $\beta$, Germany) kullanılmıştır. Yöntemin uygulanması sırasında cam şırıngalara üç paralel olarak, yaklaşık $200 \mathrm{mg}$ yem örneği tartılıp, gaz oluşumunu sağlamak için şırıngaların içerisine $40 \mathrm{ml}$ rumen sıvıs1, makro element, iz element, tampon, resazurin ve redüksiyon çözeltileri karışımı eklenmiştir. 
Araştırmada kullanılan rumen sıvısı karışımı; $620 \mathrm{ml}$ saf su $+310 \mathrm{ml}$ makro element çözeltisi $+0.16 \mathrm{ml}$ iz element çözeltisi $+310 \mathrm{ml}$ tampon çözelti $+1.6 \mathrm{ml}$ resazurin ve redüksiyon çözeltilerinden oluşmuştur. $\mathrm{Bu}$ işlemden sonra tüpler $39^{\circ} \mathrm{C}^{\prime}$ deki su banyosunda tutulmuş ve şırıngalarda oluşan gaz hacmi 3, 6, 12, 24, 48, 72 ve 96 saatlik inkübasyon süreleri sonunda kaydedilmiş ve elde edilen veriler Ørskov ve McDonald (1979) tarafından geliştirilen $\mathrm{P}=\mathrm{a}+\mathrm{b}\left(1-\mathrm{e}^{-\mathrm{ct}}\right)$ eksponansiyel denklemine uyarlanmış olan $\mathrm{GP}=\mathrm{a}+\mathrm{b}\left(1-\mathrm{e}^{-\mathrm{ct}}\right)$ eksponansiyel denklem kullanılarak Neway bilgisayar programında (Chen 1994) hesaplanmıştır. $\mathrm{Bu}$ denklemde;

GP: Süreye (t) bağlı olarak substrattan elde edilen gaz üretimini $(\mathrm{mL})$

a: Kolay parçalanan kısım (mL)

b: Zor parçalanan kısım (mL)

$\mathrm{a}+\mathrm{b}$ : Toplam (potansiyel) gaz üretimini $(\mathrm{mL})$

c: Gaz üretim hız sabitini (saat-1 veya \%)

t: Gaz üretim süresini (saat), göstermektedir.

\section{İstatistiksel Analizler}

Araştırmadan elde edilen verilerin istatistikî olarak değerlendirilmesinde SPSS (1999) istatistiki paket programı kullanılarak varyans analizi (General Linear Model) yapılmış ortaya çıkan farklılıkların önem seviyelerinin tespitinde Duncan çoklu karşılaştırma testinden faydalanılmıştır Araştırma sonucunda elde edilen veriler (SPSS, 1999) istatistik paket programında GLM prosedürü kullanılarak yerbademi genotiplerinin 3., 6., 12., 24., 48., 72. ve 96. Saatlerde sindirilebilirlikleri ile a, b, c ve a+b özelliklerinin varyans analizleri yapılmıştır. Yapılan varyans analizi sonucu istatistiki bakımdan önemli bulunan özelliklerin ortalamaları Tukey (\%5) çoklu karşılaştırma testi uygulanarak ele alınan özelliklerin grupları belirlenmiştir. Yer bademinin rumen sıvısında 3., 6., 12., 24., 48., 72. ve 96. saatlerde sindirilebilirlikleri ile a, b, c ve a+b özelliklerinin korelasyon testleri yapılarak istatistiksel olarak ilişkilerin önemi ve derecesi tespit edilmiştir.

\section{BULGULAR VE TARTIŞMA}

Yer bademi çeşitlerine ait besin madde analiz sonuçları Çizelge 1'de verilmiştir. Farklı yer bademi çeşitlerine ait değişik zamanlardaki ortalama gaz üretimleri Çizelge 2'de; 96 saatlik inkübasyonundan sonraki in vitro gaz üretim kinetikleri Çizelge 3 'de; in vitro inkübasyon zamanları ile pearson korelasyon katsayıları Çizelge 4'te; a, b, c, a+b'nin pearson korelasyon katsayıları Çizelge 5'te; farklı yer bademi çeşitlerinin gaz üretimine etkisi Şekil 1'de gösterilmiştir.

Denemede kullanılan 3 farklı yer bademi çeşitinin KM içerikleri arasında istatistiki bir farklılık görülmektedir. Kuru madde içeriklerinin çeşit bazında sıralanışı Sarı şeker (\%94.62), İntrodüksiyon 1 (\%93.86) ve Bal yumru (\%93.75) şeklindedir. Literatür çalışmalarında işleme tekniğinin yer bademinin KM'si üzerine etkisinin olduğuna dair çalışmalara rastlanılmıştır. Bu çalışmalardan birisinde yer bademinin KM içeriğinin, yüksek KM içeriğinden düşüğe doğru; kurutulmuş yer bademi (\%93.67), işlem görmemiş yer bademi (\%90.63) ve ıslatılmış yer bademi (\%90.63) şeklinde sıralandığı ifade edilmiştir (Aduwamai ve ark., 2018). Madaki ve ark., (2018) ise KM içeriğinin, işlem görmüş yer bademi (\%92.11), işlem görmemiş yer bademi (\%90.33) şeklinde sıralandığını bildirmiştir. Yine Monago ve Uwakwe (2009), KM içeriğini \%90.26; Chinma ve ark., (2011), \%89.80 olarak bulmuştur. Yer bademinin KM içeriği bölge ve ülkelere göre değişiklik gösterir. Bu konudaki bir çalışmada İspanyadaki çeşitlerde KM içeriği \%91.3-92.9 bulunurken; diğer çeşitlerde \%93.1-93.4 arasında bulunmuştur (Thomas, 2014). Imo ve ark., (2019) ise KM değerini \%95.70 olarak tespit etmiştir. 
Çizelge 1. Yer bademi çeşitlerine ait besin madde analiz sonuçları

\begin{tabular}{lccccc}
\hline \multicolumn{1}{c}{ Özellikler } & Sarı şeker & Introdüksiyon 1 & Bal yumru & OSH & P \\
\hline KM, \% & $94.62 \mathrm{a}$ & $93.86 \mathrm{~b}$ & $93.75 \mathrm{~b}$ & 0.172 & $<0.001$ \\
$\mathrm{HP}, \% \mathrm{KM}$ & $4.45 \mathrm{a}$ & $4.41 \mathrm{a}$ & $4.32 \mathrm{a}$ & 0.127 & 0.942 \\
$\mathrm{HY}, \% \mathrm{KM}$ & $28.43 \mathrm{a}$ & $25.84 \mathrm{~b}$ & $20.28 \mathrm{c}$ & 1.523 & $<0.001$ \\
$\mathrm{HK}, \% \mathrm{KM}$ & $2.65 \mathrm{a}$ & $2.52 \mathrm{~b}$ & $2.42 \mathrm{c}$ & 0.044 & 0.005 \\
$\mathrm{NDF}, \% \mathrm{KM}$ & $23.86 \mathrm{~b}$ & $21.72 \mathrm{c}$ & $26.51 \mathrm{a}$ & 0.882 & 0.001 \\
$\mathrm{ADF}, \% \mathrm{KM}$ & $14.91 \mathrm{a}$ & $14.01 \mathrm{a}$ & $16.21 \mathrm{a}$ & 0.484 & 0.168 \\
$\mathrm{ADL}, \% \mathrm{KM}$ & $5.64 \mathrm{a}$ & $5.77 \mathrm{a}$ & $5.74 \mathrm{a}$ & 0.140 & 0.960 \\
$\mathrm{LOK}, \% \mathrm{KM}$ & $40.61 \mathrm{~b}$ & $45.51 \mathrm{a}$ & $46.47 \mathrm{a}$ & 1.152 & 0.001 \\
$\mathrm{HES}, \% \mathrm{KM}$ & $8.94 \mathrm{a}$ & $7.71 \mathrm{a}$ & $10.30 \mathrm{a}$ & 0.537 & 0.103 \\
$\mathrm{HS}, \% \mathrm{KM}$ & $9.26 \mathrm{a}$ & $8.24 \mathrm{a}$ & $10.47 \mathrm{a}$ & 0.516 & 0.229 \\
$\mathrm{ME}, \mathrm{Mcal} / \mathrm{kg} \mathrm{KM}$ & $2.64 \mathrm{a}$ & $2.67 \mathrm{a}$ & $2.59 \mathrm{a}$ & 0.017 & 0.123 \\
$\mathrm{NEL}, \mathrm{Mcal} / \mathrm{kg} \mathrm{KM}$ & $1.67 \mathrm{a}$ & $1.69 \mathrm{a}$ & $1.63 \mathrm{a}$ & 0.011 & 0.123 \\
$\mathrm{SE}, \mathrm{Mcal} / \mathrm{kg} \mathrm{KM}$ & $3.22 \mathrm{a}$ & $3.25 \mathrm{a}$ & $3.16 \mathrm{a}$ & 0.020 & 0.123 \\
TSBM, \%KM & $72.98 \mathrm{a}$ & $73.78 \mathrm{a}$ & $71.59 \mathrm{a}$ & 0.468 & 0.077 \\
\hline
\end{tabular}

KM: Kuru madde; HK: Ham kül; HP: Ham protein; HY: Ham yă̆; NDF: Nötr deterjan çözeltisinde çc̈zünmeyen lif; ADF: Asit deterjan çözeltisinde çözünmeyen lif; ADL: Asit deterjan lignin; HS: Ham selüloz; HES: Hemiselüloz; LOK: Lifsiz karbonhidrat; TSBM: Toplam sindirilebilir besin maddesi; SE: Sindirilebilir enerji; ME: Metabolize olabilir enerji; NEL: Net enerji laktasyon; OSH: Ortalamalara ait standart hata; P: Olasılık değeri; ${ }^{\text {a-d. }}$ Aynı sütunda farklı harflerle gösterilen ortalamalar arasındaki farklılıklar istatistiki açıdan önemlidir $(\mathrm{P}<0.05)$.

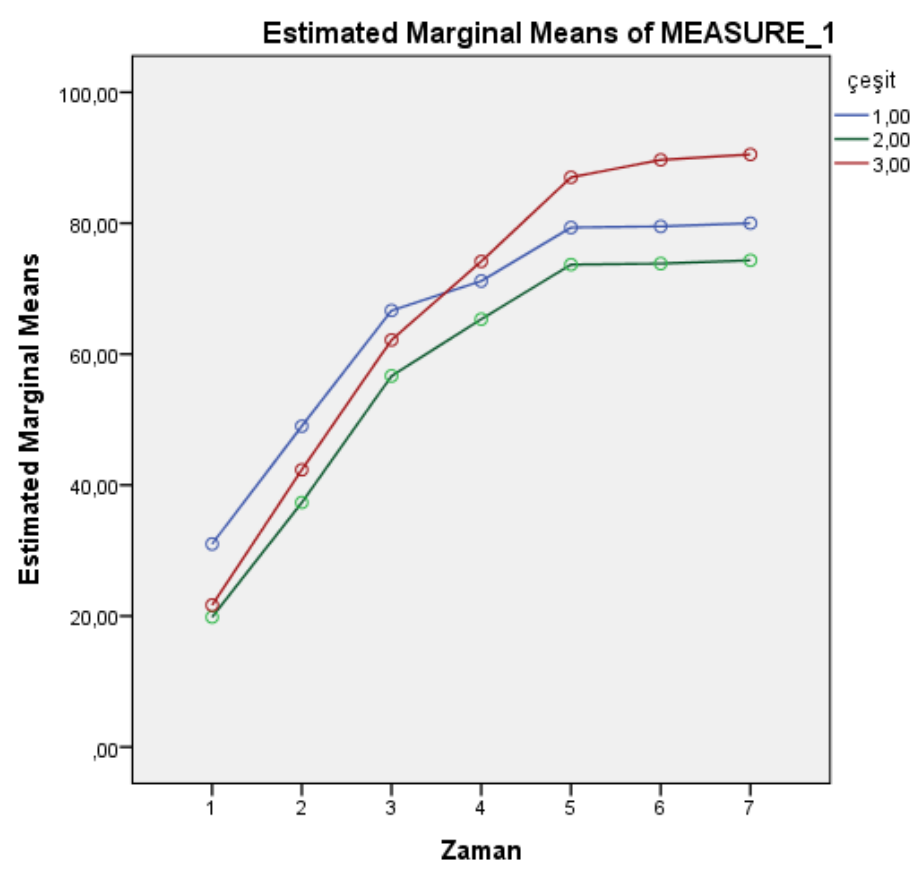

Şekil 1. Farklı yer bademi çeşitlerinin gaz üretimine etkisi

Yer bademi çeşitlerinin HP oranları, çalışmamızda çeşit bazında istatistiki olarak önemsiz bulunmuştur ( $\mathrm{P}>0.05)$. HP oranlarının sıralanışı Sarı şeker (\%4.45), İntrodüksiyon 1 (\%4.41), Bal yumru (\%4.32) şeklinde olmuştur. Yapılan bir çalışmada HP ortalaması 7.94 olarak bulunurken (Monago ve Uwakwe, 2009); Ozcan ve ark., (2010) \%8.11; Chinma ve ark., (2011), \%10.1; Gambo ve Da'u (2014)'da, \%7.15-9.70 aralığında tespit etmiştir. Maduka ve Ire (2018), yer bademi çeşitlerinin HP 
değerlerini 1slak veya kuru olmasına bağlı olarak \%3.65-4.82; 3.94-7.94 olarak saptamışlardır. Yapılan çalışmalar incelendiğinde HP içeriklerinde farklılıklar görülmüştür. Bunun sebebi işleme teknikleri, hasat zamanının farklı olması, kullanılan çeşit veya hatların farklı olması, analiz metotlarının farklı olması ile bölgelerin değişik olması sayılabilir.

Çalışmamızda yer bademinin HY oranları çeşitlerde istatistiki bir farklılık yaratmıştır $(\mathrm{P}<0.05)$. Ham yă̆ oran1, işleme teknolojisine, çeşit, kurutmaya göre farklılık arz etmekle beraber, HY düzeyini Monago ve Uwakwe (2009), \%19.67-27.54; Chinma ve ark., (2011), \%13.2; Bado ve ark., (2015) \%24.91-28.94; Achoribo ve Ong (2017), \%30; Emurotu (2017), \%22.4; Zommara ve Imaizumi (2017), \%25; Madaki ve ark., (2018), \%25.53-\%28.61; Maduka ve Ire (2018)'de \%24.49 olarak saptamışlardır. Maduka ve Ire (2018), ayrıca yer bademi çeşitlerinin HY değerlerini ıslak veya kuru olmasına bağlı olarak \%11.50-14.10; 19.67-27.54 arasında tespit etmişlerdir.

Çalışmamızda HK değeri Sarı şeker çeşidinde \%2.65; İntrodüksiyon 1 çeşidinde \%2.52, Bal yumru çeşidinde de \%2.42 olarak tespit edilmiştir $(\mathrm{P}<0.05)$. Karababa ve ark., (2004), yer bademindeki HK içeriğinin \%1.90-6.70 arasında değişim gösterdiğini ifade etmiştir. Yapılan bir çalışmada yer bademinin HK içeriğinin \%3.1 olduğu tespit edilmiştir (Chinma ve ark., 2011). Maduka ve Ire (2018), yer bademi çeşitlerinin HK değerlerini ıslak veya kuru olmasına bağlı olarak \%1.75-1.80; \%1.79-2.68 olarak saptamışlardır. Imo ve ark., (2019) ise HK değerini \%1.90 olarak tespit etmiştir.

Yer bademine ait ADF ve ADL içerikleri, çeşitler bazında istatistiki olarak önemli bulunmazken; NDF içerikleri önemli bulunmuştur $(\mathrm{P}<0.05)$. ADF oranı \%14.01-16.21; ADL oranı da \%5.64-5.77 arasında bulunurken; NDF oranı çeşitlerde \%21.72-26.51 arasında tespit edilmiştir. NDF oranlarının sıralanışı Bal yumru (\%26.51), Sarı şeker (\%23.86), İntrodüksiyon 1 (\%21.72) şeklinde olmuştur.

Çalışmamızda HS, Bal yumru çeşidinde \%10.47 ile en yüksek değeri alırken; İntrodüksiyon 1 çeşidinde \%8.24 ile en düşük değeri almış, Sarı şeker çeşidi de \%9.26 değerini alırken; ortalama HS oranı da \%9.32 olarak bulunmuştur ( $\mathrm{P}>0.05)$. Bu konuda yapılan çalışmalarda HS oranının bölgelere, ülkelere göre farklı değerler aldığı ifade edilmiş, ülkemizdeki çeşitlerde \%8.7 olan HS oranının, İspanyadaki çeşitlerde \%9.8-11.0 arasında olduğu gözlemlenmiştir (Thomas, 2014). Karababa ve ark., (2004), yer bademindeki HS içeriklerinin geniş bir dağılım izlediğini bildirerek, HS oranının \%4.8-13.0 arasında değişim gösterdiğini ifade etmiştir. Monago ve Uwakwe (2009), HS düzeyini \%15.60-21.36 olarak bulurken; Chinma ve ark., (2011), HS düzeyini, denemede elde ettiğimiz değerden düşük bulmuştur (\%4.3). Bunun nedeni kullanılan çeşitler ile yetiştirme yerlerinin, bölgelerin ve analiz metotlarının farklı olmasıdır. Zommara ve Imaizumi (2017), HS düzeyini \%8; Bobreneva ve Baioumy (2018), \%15.37; Madaki ve ark., (2018), \%22.34-24.94; Maduka ve Ire (2018)'de \%8.91 olarak tespit etmiştir. Ayrıca Maduka ve Ire (2018), yer bademi çeşitlerinin HS değerlerini ıslak veya kuru olmasına bağlı olarak \%15.27-18.0; \%15.60-21.36 olarak saptamışlardır. Imo ve ark., (2019) ise HS değerini $\% 10.12$ olarak tespit etmişlerdir.

Hemiselüloz değerleri (HES), denememizde \%7.71-10.30 arasında değişim göstermiştir. HES oranlarının sıralanışı Bal yumru (\%10.30), Sarı şeker (\%8.94) ve İntrodüksiyon 1 (\%7.71) şeklinde olmuştur. Lifsiz karbonhidrat (LOK) içeriği, çeşitler arasında bir farklılık yaratmış $(\mathrm{P}<0.05)$; Bal yumru çeşidi \%46.47 ile en yüksek LOK'a sahip iken; İntrodüksiyon 1 çeşidi \%45.51; Sarı şeker çeşidi de \%40.61 değerini almışlardır. Ortalama LOK içeriği de \%44.20 olarak saptanmıştır.

Yer bademi çeşitlerine ait TSBM, SE, ME ve NEL değerleri istatistiki olarak önemsiz bulunmuştur. Çeşitlere ait TSBM, SE, ME ve NEL değerleri ortalama \%72.78, $3.21 \mathrm{Mcal} / \mathrm{kg}, 2.63$ $\mathrm{Mcal} / \mathrm{kg}$ ve $1.66 \mathrm{Mcal} / \mathrm{kg}$ bulunmuştur. TSBM, en fazla İntrodüksiyon 1 çeşidinde, en az da Bal yumru çeşidinde tespit edilmiştir. Maduka ve Ire (2018), yer bademi çeşitlerinin enerji değerlerini sslak veya kuru olmasına bağlı olarak 183.50-213.90; 317.61-326.02 olarak saptamışlardır. Sindirilebilir enerji 
değeri ile ME değeri, en fazla İntrodüksiyon 1 çeşidinde görülmüştür. NEL değeri de $1.69 \mathrm{Mcal} / \mathrm{kg}$ ile İntrodüksiyon 1 çeşidinde en yüksek bulunurken, $1.63 \mathrm{Mcal} / \mathrm{kg}$ ile Balmumu çeşidinde en düşük saptanmıştır.

Çalışmada kullandığımız yer bademi çeşitlerine ait farklı zamanlardaki ortalama gaz üretimleri Çizelge 2'de gösterilmiştir. Çeşitlerin ortalama gaz üretimleri sadece 3.saatte bir farklılık yaratırken; diğer farklı zamanlarda istatistiki bir farklılık oluşmamıştır. 3.saatteki gaz üretimi İntrodüksiyon 1, Bal yumru, Sarı şeker şeklindedir. Toplam gaz üretimine bakıldığında Bal yumru çeşidinde $88.51 \mathrm{ml} / 200$ mg bulunan ortalama gaz üretimi, İntrodüksiyon 1 çeşidinde 74.84; Sarı şeker çeşidinde de 69.34 ml/200 mg olarak saptanmıştır.

Ayaşan ve ark., (2020), en yüksek gaz üretimini 96.saatte $56.44 \mathrm{ml} / 200 \mathrm{mg}$ ile İntrodüksiyon 1 çeşidinden elde ederken; Bal yumru çeşidinde bu değer $39.10 \mathrm{ml} / 200 \mathrm{mg}$; Sarı şeker çeşidinde de 36.60 $\mathrm{ml} / 200 \mathrm{mg}$ olarak tespit edilmiştir.

Çizelge 2. Farklı yer bademi çeşitlerinin değişik zamanlardaki ortalama gaz üretimleri

\begin{tabular}{llllllll}
\hline Çeşitler & 3.saat & 6.Saat & 12.Saat & 24.Saat & 48.Saat & 72.Saat & 96.Saat \\
\hline İntrodüksiyon 1 & $31.00 \mathrm{a}^{*}$ & 49.00 & 66.67 & 71.17 & 79.34 & 79.50 & 80.00 \\
Sarı şeker & $19.83 \mathrm{~b}$ & 37.34 & 56.67 & 65.34 & 73.67 & 73.83 & 74.33 \\
Bal yumru & $21.67 \mathrm{~b}$ & 42.34 & 62.17 & 74.17 & 87.01 & 89.68 & 90.50 \\
OSH & 2.02 & 2.38 & 2.78 & 3.70 & 4.62 & 4.71 & 4.75 \\
P & .020 & .123 & .387 & .674 & .562 & .435 & .423 \\
\hline
\end{tabular}

$* \mathrm{P}<0.05$, OSH: Ortalamalara ait standart hata

Yer bademi çeşitlerinin 96 saatlik inkübasyondan sonraki in vitro gaz üretim kinetikleri Çizelge 3'de verilmiştir. Burada yemin yapay rumene konulduğu ilk anda oluşan gaz hacmi (a), süreye bağlı olarak oluşan gaz hacmi (b) ve toplam (potansiyel) gaz üretimi $(a+b)$ bakımından çeşitler arasında bir farkl1lık görülmemiştir.

Çizelge 3. Yer bademi çeşitlerinin 96 saatlik inkübasyonundan sonraki in vitro gaz üretim kinetikleri

\begin{tabular}{lcccc}
\hline Çeşitler & $\mathbf{a}$ & $\mathbf{b}$ & $\mathbf{c}$ & $\mathbf{a}+\mathbf{b}$ \\
\hline Introdüksiyon 1 & 5.57 & 73.13 & 0.15 & 78.70 \\
Sarı şeker & -2.41 & 75.69 & 0.12 & 73.28 \\
Bal yumru & 3.81 & 85.02 & 0.09 & 88.83 \\
OSH & 2.15 & 10.43 & 0.01 & 4.76 \\
$\mathrm{P}^{*}$ & .317 & .492 & .245 & .458 \\
\hline
\end{tabular}

*P>0.05, OSH: Ortalamalara ait standart hata

Bu konuda yapılan az sayıdaki bir çalışmada, yer bademi çeşitlerinin 96 saatlik inkubasyonundan sonraki in vitro gaz üretim kinetikleri araştırılmış, toplam (potansiyel) gaz üretimi $(\mathrm{a}+\mathrm{b})$ bakımından çeşitler arasında bir farklılık görülmüştür (Ayaşan ve ark., 2020). Bu çalışma ile denemede elde edilen çalışma arasındaki farklılığın, kullanılan hayvanların farklı (inek ve koç) olması olduğu düşünülmektedir.

Yer bademinin rumen sıvısında in vitro inkübasyon zamanı ile pearson korelasyon katsayıları pozitif yönde değerler almıştır (Çizelge 4). Korelasyon katsayısının pozitif çıkması, iki değişkenin aynı yönde bir ilişkide olduğunu ifade ederken, negatif (-) çıkması iki değişkenin arasında ters yönde bir ilişki olduğunu göstermektedir. 2 değişken arasındaki ilişkinin derecesini saptamada ölçüt olan korelasyon 
katsayısı, çalışmada 3.saat ile 6.saat arasında 0.01 düzeyinde pozitif bir ilişki içerisinde bulunurken; 3.saat ile 12.saat arasında 0.05 düzeyindeki korelasyon önemli bulunmuştur. Pearson korelasyon katsayısı, iki değişkenin de sürekli olmasını ve değişkenlerin birlikte normal dă̆glım göstermesini gerektirmektedir. Değişkenler arasında korelasyon katsayısının 1 olması, aralarında mükemmel bir ilişkinin olduğunu göstergesi olarak kabul edilir. Korelasyon katsayısının 0.70-1.00 arasında olması, korelasyonun yüksek olduğunu tarif eder. Ayaşan ve ark., (2020), in vitro inkübasyonuyla üretilen yer bademine ait gaz miktarlarının, zaman içinde oldukça korelasyonlu olduğunu, bu nedenle, 96 saatlik in vitro inkübasyonun gerekenden daha uzun olabildiğini ifade etmiştir. Çalışmamızda da in vitro inkübasyon zamanları ile pearson korelasyon katsayıları arasında pozitif bir ilişki saptanmıştır.

Çizelge 4. In vitro inkübasyon zamanları ile pearson korelasyon katsayıları

\begin{tabular}{lllllllll}
\hline Pearson Korelasyon & 3.saat & 6.Saat & 12.Saat & 24.Saat & 48.Saat & 72.Saat & 96.Saat & Toplam \\
\hline 3.saat & 1 & $.927^{* *}$ & $.792^{*}$ & .521 & .419 & .358 & .348 & .286 \\
6.Saat & & 1 & $.956^{* *}$ & $.769^{*}$ & $.700^{*}$ & .652 & .644 & .591 \\
12.Saat & & & 1 & $.901^{* *}$ & $.851^{* *}$ & $.810^{* *}$ & $.803^{* *}$ & $.758^{*}$ \\
24.Saat & & & & 1 & $.983^{* *}$ & $.962^{* *}$ & $.957^{* *}$ & $.929^{* *}$ \\
48.Saat & & & & & 1 & $.994^{* *}$ & $.991^{* *}$ & $.976^{* *}$ \\
72.Saat & & & & & & 1 & $1.000^{* *}$ & $.994^{* *}$ \\
96.Saat & & & & & & & 1 & $.996^{* *}$ \\
\hline
\end{tabular}

**. Korelasyon $\mathrm{P}<0.01$ 'de önemlidir (2-tailed).

Çizelge 5. a, b, c, a+b’nin pearson korelasyon katsayıları

\begin{tabular}{lllll}
\hline Pearson Katsayıları & $\mathbf{a}$ & $\mathbf{b}$ & $\mathbf{c}$ & $\mathbf{a + b}$ \\
\hline $\mathrm{a}$ & 1 & -0.040 & -0.355 & 0.098 \\
$\mathrm{~b}$ & & 1 & -0.107 & $0.991^{\text {*** }}$ \\
$\mathrm{c}$ & & & 1 & -0.155
\end{tabular}

**. Korelasyon $\mathrm{P}<0.01$ 'de önemlidir (2-tailed).

Çizelge 5'e bakıldığında süreye bağlı olarak oluşan gaz hacmi (b) (mL) ile toplam (potansiyel) gaz üretimi $(\mathrm{a}+\mathrm{b})$ arasındaki korelasyonun istatistiki olarak 0.01 düzeyinde önemli olduğu görülmüştür $(\mathrm{P}<0.01)$. Korelasyonun eksi olması, ters bir ilişkiyi ifade etmektedir. Yani yemin yapay rumene konulduğu ilk anda oluşan gaz hacmi (a), süreye bağlı olarak oluşan gaz hacmi (b) ve c arasında ters bir ilişki vardır. Yine c ile $\mathrm{a}+\mathrm{b}$ arasında da benzer durum bulunmaktadır. Bu konuda yapılan çalışmaların az olması nedeniyle, bazı parametrelerde tartışma yeterince yapılamamıştır.

\section{SONUÇ}

Denemede elde edilen sonuçlar değerlendirildiğinde yer bademine ait in vitro inkübasyon zamanları ile pearson katsayıları arasında önemli bir ilişki bulunmuş, yer bademi çeşitlerinin KM, HK, HY, NDF, HS düzeyleri istatistiki olarak çeşitler bazında önemli bulunmuştur. Yer bademine ait in vitro gaz üretimine ait literatür bilgisi bulunamadığından, bundan sonraki çalışmalarda bu konu ile ilgili daha farklı çalışmalara gereksinim olduğu düşüncesindeyiz. Yer bademinin bazı nedenlerden dolayı kısıtlı bir alanda ekiminin yapılması nedeniyle, bu konuda yeni çalışmalar yapılarak, ekiminin artırılması yönünde çalışmalar yanında, mekanizasyon kaynaklı problemlerin bir an önce giderilmesi de gerekmektedir.

\section{Çıkar Çatışması}

Makale yazarları aralarında herhangi bir çıkar çatışması olmadığını beyan ederler. 


\section{Yazar Katkısı}

Yazarlar makaleye eşit oranda katkı sağlamış olduklarını beyan ederler.

\section{KAYNAKLAR}

Achoribo ES, Ong MT, 2017. Tiger nut (Cyperus Esculentus): Source of natural anticancer drug? Brief review of existing literature. Euromediterranean Biomedical Journal, 12(19): 091-094.

Aduwamai UH, John UI, Aminu A, Isaac UK, 2018. Influence of different processing methods on proximate and anti-nutritional value of tigernuts (Cyperus esculentus L.). GSC Biological and Pharmaceutical Sciences, 03(03): 029-034.

Anonim, 2019a. Tigernuts /Chufas. https://www.tigernuts.com/pdf/tigernuts.profile.pdf

Anonim, 2019b. Yerbademi. https://www.tunaproject.com.tr/urunler-321269/tarimsal-urunler/superfoods/detay/417425/yer-bademi--tiger-nuts-.

Association of Official Analytical Chemists, AOAC, 1990. Official Method of Analysis. 15th. ed. Washington, DC. USA.

Ayaşan T, Ülger İ, Kaliber M, Ergül Ş, İnci H, Mart D, Türkeri M, 2018. Comparison of in vitro gas production, nutritive value, metabolizable energy and organic matter digestibility of some chickpea varieties. Iranian Journal of Applied Animal Science, 8(1):131-136.

Ayaşan T, Sucu E, Ülger İ, Hızlı H, Cubukcu P, Özcan BD, 2020. Determination of in vitro rumen digestibility and potential feed value of tiger nut varieties. South African Journal of Animal Science, 50(5): 738-744.

Bado S, Bazongo P, Son G, Kyaw MT, Forster BP, Nielen S, Lykke AM, Ouédraogo A, Bassolé IHN, 2015. Physicochemical characteristics and composition of three morphotypes of cyperus esculentus tubers and tuber oils. Journal of Analytical Methods in Chemistry, Article ID 673547, 8 pages http://dx.doi.org/10.1155/2015/673547.

Bilgili ME, Çubukcu P, Vurarak Y, 2018. Yerbademinin tarımı ve mekanizasyonunun değerlendirilmesi. Uluslararası Doğu Akdeniz Tarımsal Araştırma Enstitüsü Dergisi, 1(2): 20-33.

Bobreneva IV, Baioumy AA, 2018. Effect of using tiger nuts (Cyperus esculentus L.) on nutritional and organoleptic characteristics of beef burger. Bioscience Research, 15(3): 1424-1432.

Chen XB, 1994. Neway excel. an excel application programme for processing feed degradability data. User Manual. Int. Feed Resources Unit. Rowrett Research Institute. Scotland (Unpublished).

Chinma CE, James S, Imam H, Ocheme OB, Anuonye JC, Yakubu CM, 2011. Physicochemical and sensory properties, and in vitro digestibility of biscuits made from blends of tigernut (Cyperus esculentus) and pigeon pea (Cajanus cajan). Nigerian Journal of Nutritional Sciences, 32(1): 5562.

Emurotu JE, 2017. Comparison of the nutritive value of the yellow and brown varieties of tigernut. IOSR Journal of Applied Chemistry, 10(9): 29-32.

Eseceli H, Ayaşan T, Esen VK, Esen S, 2020. Nutrient and mineral contents and in vitro digestibility of kermes oak (Quercus coccifera L.) and mock privet (Phillyrea latifolia L.). Alınteri Zirai Bilimler Dergisi, 35(2): 100-106.

Gambo A, Da'u A, 2014. Tigernut (Cyperus esculentus L.): Composition, products, uses and health benefits-A review. Bayero Journal of Pure and Applied Sciences, 7(1): 56-61. 
Gutierrez N, Boyd JA, 2020. Effects of in vitro digestibility in cannulated steers when supplemented different levels of glycerol. Journal of Animal Science, 98(2): 55-56.

He Y, Cone JW, Hendriks WH, Dijkstra J, 2019. Relationships between chemical composition and in vitro gas production parameters of maize leaves and stems. J. Anim. Physiol. Anim. Nutr. 104(1): 12-21.

Imo C, Uhegbu FO, Arowora KA, Ezeonu CS, Opara IJ, Nwaogwugwu CJ, Anigbo CJ, 2019. Chemical composition of Cyperus esculentus nut and phoenix dactylifera fruit. African Journal of Biotechnology, 18(19): 408-415.

İnce A, Vursavuş KK, Vurarak Y, Çubukcu P, Çevik MY, 2017. Selected engineering properties of tiger nut as a function of moisture content and variety. Turkish Journal of Agriculture Foresty, 41: 263271.

Kamalak A, Atalay AI, Ozkan CO, Kaya K, Tatliyer A, 2011. Determination of nutritive value of Trigonella kotschi Fenzl hay harvested at three different maturity stages. Kafkas Univ. Vet. Fak. Dergisi, 17: 635-640.

Kara K, 2020. Determination of the in vitro digestibility and nutrient content of commercial premium extruded foods with different types of protein content for adult dogs. Veterinarni Medicina, 65(6): 233-249.

Karababa E, Coşkuner Y, Nazlıcan A, 2001. Çufa yumrusunun kimyasal bileşimi ve teknolojik değerlendirilmesi. G1da, 26(4): 243-246.

Kaya E, Canbolat O, Atalay AI, Kurt O, Kamalak A, 2016. Potential nutritive value and methane production of pods, seed and senescent leaves of Gleditsia triacanthos trees. Livestock Research for Rural Development, 28(7): 123.

Madaki FM, Kabiru AY, Muhammad HL, Abubakar AN, Bello A, 2018. Comparative nutritional compositions of raw and processed tiger nuts (Cyperus esculentus L.). IJABR, 9(2): 32-40.

Maduka N, Ire FS, 2018. Tigernut plant and useful application of tigernut tubers (Cyperus esculentus)A review. http://www.sdiarticle2.org/prh/CJAST_68/2018/Revised-ms_CJAST_43551_v4.pdf

MAFF, 1984. Energy allowances and feeding systems for ruminants. Her Majesty's Stationary Office London, UK.

Menke KH, Steingass H, 1988. Estimation of the energetic feed values obtained from chemical analysis and in vitro gas production using rumen liquid. Anim. Res. Dev. 28: 7-55.

Monago CC, Uwakwe AA, 2009. Proximate composition and in vitro anti sickling property of Nigerian Cyperus esculentus (tiger nut sedge). Trees for Life Journal, 1-6.

Nazlıcan AN, 2007. Yağ, nişasta ve şeker üretiminde yeni bir alternatif: Yerbademi. Agroskop Tarım Gıda Hayvancılık Dergisi, 1(1): 54-55.

Ortis CAN, Roa Vega MG, 2020. Determination of in vitro digestibility of forage species used in ruminant feding. Tropical Animal Health and Production, 52: 3045-3059.

Ozcan MM, Gumuscu A, Er F, Arslan D, Ozkalp B, 2010. Chemical and fatty acid composition of cyperus esculentus. Chemistry of Natural Compounds, 46(2): 276-277.

Ørskov ER, McDonald I, 1979. The estimation of protein degradability in the rumen from incubation measurements weighed according to rate of passage. J. Agric. Sci, 92: 499-503.

Sidohounde A, Nonviho G, Djenontin ST, Agbangnan P, Paris C, Sohounhloue DCK, 2014. Physicochemical characterization of vegetable oil and defatted meal from two varieties of cyperus esculentus from Benin. Chemistry Journal, 4(1): 1-7.

SPSS Statistical Package for the Social Sciences for Windows, 1999. Spps Inc., Chicago, Illinois, USA. 
Suleiman MS, Olajide JE, Omale JA, Abbah OC, Ejembi DO, 2018. Proximate composition, mineral and some vitamin contents of tigernut (Cyperus esculentus). Clin. Invest. (Lond.), 8(4): 161-165.

Thomas AD, 2014. Physical, chemical and functional properties of tiger nuts (cyperus esculentus) selected from Ghana, Cameroon and UK Market (Spain). University of Plymouth Research Theses, Doctoral Thesis, p:254.

Turan A, Soycan Önenç S, 2018. Effect of cumin essential oil usage on fermentation quality, aerobic stability and in vitro digetibility of alfalfa silage, Asian-Australasian Journal of Animal Sciences, 31: 1252-1258.

Türel AO, Buğdayc1 KE, 2020. Nutrient content and in vitro digestibility of kermes oak (Quercus coccifera L.) growing in the provincial borders of Burdur. Ankara Üniversitesi Veteriner Fakültesi Dergisi, 67(1): 95-100.

Ülger İ, Kaliber M, Büyükkılıç Beyzi S, Konca Y. 2020a. Possible ensiling of pumpkin (Cucurbita pepo) residues. Turkish Journal of Veterinary \& Animal Sciences, 44(4): 853-859.

Ülger I, Büyükkılıç Beyzi S, Kaliber M, Konca Y. 2020b. Chemical, nutritive, fermentation profile and gas production of citrus pulp silages, alone or combined with maize silage. South African Journal of Animal Science, 50(1): 161-169.

Van Soest PJ, Wine RH, 1967. Use of detergents in the analysis of fibrous feeds. IV. Determination of plant cell-wall constituents. Journal of the Association of Official Analytical Chemists, 50: 50-55.

Van Soest PJ, Robertson JD, Lewis BA, 1991. Methods for dietary fibre, neutral detergent fibre and non-starch polysaccharides in relation to animal nutrition. Journal of Dairy Science, 74: 35833597.

Weiss WP, Conrad HR, St Pierre NR, 1992. A theoretically-based model for predicting total digestible, nutrient values of forages and concentrates. Animal Feed Science and Technology, 39(1-2): 95110.

Y1lmaz Y, 2019. Yerbademi sütü (Horchata) yan ürünlerinin ekmek üretiminde değerlendirilmesi üzerine bir çalışma. Hacettepe Üniversitesi Gıda Mühendisliği Bölümü Yüksek Lisans Tezi, s:140, Ankara.

Zommara M, Imaizumi K, 2017. In vitro antioxidant activity of chufa tubers (cyperus esculentus l.) extracts in liposome peroxidation systems. Journal of Sustainable Agricultural Sciences, 43(2): 69-76. 